PALABRAS CLAVE

Crecimiento económico

Disparidad económica

Geografía

Historia económica

Aspectos políticos

Aspectos sociales

Movilidad social

Análisis económico

Modelos matemáticos

América Latina

José Antonio Alonso

Catedrático de Economía Aplicada

Director del Instituto Complutense

de Estudios Internacionales (ICEI)

Madrid

$\propto$ j.alonso@ccee.ucm.es
REVISTA DE LA CEPAL 93・DICIEMBRE 2007

\section{Desigualdad, instituciones y progreso: un debate entre la historia y el presente}

\author{
José Antonio Alonso
}

$\mathrm{E}$

artículo analiza las interpretaciones existentes sobre los factores explicativos del crecimiento económico de largo plazo, con especial atención al caso de América Latina. En concreto, el autor entra en debate tanto con aquellas interpretaciones que insisten en el papel que las condiciones geográficas tienen en el proceso de desarrollo como con las que aluden al papel que la colonización tuvo en la conformación de un marco institucional inadecuado para el desarrollo. Aportando una estimación propia, se subraya la importancia del acceso a mercados y el coste que la fragmentación social tiene sobre la generación de un marco institucional eficiente y creíble. Finalmente discute el papel de la desigualdad tanto sobre la calidad institucional como sobre la dinámica de crecimiento. 


\section{I}

\section{Introducción}

La teoría económica ofrece un panorama relativamente convincente de los factores más inmediatos que promueven el crecimiento económico contemporáneo: la acumulación de capital físico y humano y el progreso tecnológico se erigen como principales factores explicativos. No obstante, es difícil que estos factores, por sí solos, den cuenta de las extraordinarias desigualdades que rigen en el ámbito internacional y logren explicar el proceso secular de divergencia que está en su base (Pritchett, 1997). La tenaz persistencia del subdesarrollo desafía una interpretación simple de la dinámica económica y reclama una indagación ulterior para identificar las fuerzas que determinan el crecimiento económico de largo plazo. Se trata de explicar qué es lo que hace que aquellas variables más inmediatas hayan evolucionado de forma tan dispar entre países y regiones, lo que remite a factores más fundamentales y a marcos temporales más dilatados en la explicación del progreso económico, es decir, a las causas profundas del crecimiento de largo plazo.
En los últimos tiempos ha habido muy diversas aportaciones en este ámbito: a la tarea han contribuido economistas, politólogos, naturalistas e historiadores. El interés de estos ensayos excede al propio de la indagación histórica, en tanto que tratan de desvelar aquellos factores centrales que explican el progreso económico, debiendo inspirar, por tanto, cualquier respuesta a los problemas del subdesarrollo que se pretenda eficaz. Se trata entonces de un debate entre la historia y la actualidad. Lamentablemente, el deseo de encontrar una única y fundamental causa del desarrollo ha propiciado explicaciones sumarias, grandes interpretaciones de la tendencia secular, que no siempre dan cuenta de la complejidad de la dinámica de cambio económico y social que el desarrollo comporta. No es el propósito de estas páginas corregir esa carencia, ya que tal pretensión excedería con mucho a las capacidades de este autor. De lo que se trata, más modestamente, es de señalar algunas limitaciones asociadas a las interpretaciones dominantes y apuntar a algunos factores adicionales que debieran ser tenidos en cuenta en la explicación del proceso de desarrollo.

\section{II}

\section{Instituciones y geografía}

La literatura más reciente ofrece dos grandes hipótesis para explicar las causas últimas del desarrollo. La primera remite a la importancia decisiva de los factores geográficos: se supone que las condiciones del suelo, el clima, el entorno ecológico o la accesibilidad física determinan las posibilidades de progreso (Gallup, Sachs y Mellinger, 1998; Sachs, 2001, o Diamond, 1998). En el seno de esta tradición es posible encontrar hasta tres variantes, que apuntan a vías diferentes, aunque no incompatibles, de incidencia de los factores geográficos: i) el clima, que condiciona la disposición al esfuerzo e influye sobre la productividad de las personas; ii) la geografía, que determina las opciones tecnológicas, la productividad del suelo y las condiciones de movilidad y de transporte, y iii) la persistencia de ciertas enfermedades, que aparecen influidas por las condiciones biofísicas del entorno.

En todos estos casos son factores ajenos (o relativamente ajenos) a la influencia humana los que determinan las posibilidades de desarrollo. Las pruebas que se aportan para respaldar esta hipótesis son diversas, si bien las más influyentes aluden a las dificultades que los países localizados entre los trópicos o los que carecen de salida al mar y de vías navegables han tenido para poner en marcha una estrategia de desarrollo exitosa. Los costes de ciertas enfermedades epidémicas y su prevalencia en determinados entornos geográficos — de nuevo coincidentes con los trópicos- aportan argumentos adicionales a este enfoque interpretativo, al señalar las dificultades que para la vida y la actividad productiva tienen ciertas condiciones ambientales.

Pese a la reconocida importancia de los aspectos geográficos, no parece, sin embargo, que los defensores de esta tesis hayan aportado pruebas suficientes como para otorgar al entorno natural la condición de causa última del atraso económico. La relativa inmutabilidad de las condiciones geográficas las convierten en un improbable 
candidato para explicar las repentinas inflexiones que en la dinámica económica han experimentado numerosos países en momentos dados (piénsese, por ejemplo, en la China actual); al tiempo que es difícil que expliquen la trayectoria económica divergente de países que, por ser relativamente contiguos, comparten similar entorno geográfico (México y los Estados Unidos, por ejemplo, o la República Popular Democrática de Corea y la República de Corea).

La crítica más severa a este planteamiento la proporciona, no obstante, la regresión sufrida por ciertas sociedades que destacaban en su entorno regional en el pasado histórico y que hoy ocupan posiciones rezagadas respecto a sus vecinos: es la "reversión de la fortuna" a la que se refiere la literatura especializada. Los casos más ilustrativos de este fenómeno son las sociedades inca, azteca o mogol, que destacaron por su complejidad y riqueza hacia el año 1500 y que han pasado a ser parte del mundo en desarrollo en la actualidad. Acemoglu, Johnson y Robinson (2002) trataron de demostrar, además, que la reversión de la fortuna excede al mero recuento de casos singulares. Considerando que la urbanización es un exponente del nivel de prosperidad, confirman para una muestra de países en desarrollo la existencia de una correlación negativa entre el porcentaje de población urbana hace cinco siglos y el nivel de su producto interno bruto (PIB) per cápita actual. Tal resultado evidencia el contraste entre los cambios vividos en la posición relativa de los países y la aceptable permanencia de las condiciones geográficas en las que aquellos se ubican. La discutible calidad de los datos utilizados y los elevados niveles de dispersión de la relación debilitan, no obstante, el valor probatorio de este ejercicio.

Conviene señalar que las criticas aludidas, pese a estar bien fundadas, no logran anular el efecto que las condiciones del entorno pueden haber tenido sobre los procesos de desarrollo. En primer lugar, porque es posible que las condiciones geográficas no sean tan inmutables como se supone: alteraciones en las condiciones naturales o ambientales pueden haber contribuido a fenómenos de regresión como los citados. Los cambios en las condiciones climáticas asociadas a importantes sequías o la presión degradante sobre un entorno ecológico frágil, unido al recrudecimiento de los conflictos intergrupales por el control de los recursos, parecen haber estado detrás del colapso de sociedades relativamente evolucionadas, como las de Huari, Tiahuanaco, Calakmul o Cahokia (Diamond, 2005 o Mann, 2006). Pero, además, es posible que determinadas características del entorno sean poco significativas en un determinado contexto, pero muy mportantes en otro. Por ejemplo, es posible que la ubicación de algunas capitales latinoamericanas en zonas del interior haya sido poco relevante en el momento de su fundación, cuando los intercambios eran escasos y primaban razones defensivas en la elección de los asentamientos, pero pudo convertirse en un obstáculo para la comunicación y el transporte una vez integradas sus economías en el mercado internacional. A este respecto, la disposición de América Latina sobre un eje preferentemente vertical, la presencia de importantes accidentes montañosos que fragmentan el espacio regional y la ausencia de vías navegables de importancia debieron constituir obstáculos significativos para mover personas, desplazar cultivos, comunicar ideas y transportar mercancías. ${ }^{1}$ Ahora bien, el hecho de que los factores geográficos importen no quiere decir, necesariamente, que en ellos esté la causa del atraso económico.

Un supuesto que alimenta la hipótesis de quienes juzgan que son las instituciones (y no la geografía) las que determinan las posibilidades de desarrollo. Por instituciones se entiende el marco de incentivos (y penalizaciones) que, emanado de la sociedad, da forma a las interacciones entre los agentes, condicionando el comportamiento colectivo. Las instituciones ayudan a formar las expectativas de las gentes acerca de las respuestas del resto, reduciendo con ello los grados de incertidumbre y los costes de transacción que rigen en una sociedad. Desde una perspectiva genérica, las instituciones contribuyen a determinar los incentivos a la inversión en capital físico y humano y condicionan, por esa vía, las posibilidades de crecimiento agregado (North, 1993).

Pues bien, los defensores de este enfoque sugieren que, en el caso de los países en desarrollo, la formación del marco institucional se vio condicionada por la forma que adoptó el proceso de colonización. El tipo de asentamiento y de explotación de las tierras conquistadas por el que optaron los colonos determinó la forma que adoptaron las instituciones creadas. En este caso, la explicación del subdesarrollo no remite a factores - como la geografía - ajenos al control humano, sino a otros — como las instituciones-que son genuinos productos sociales, si bien con un origen que se remonta en la historia a la forzada inserción del país en la economía internacional.

También en esta tradición es posible encontrar diferentes variantes. Por una parte están quienes como Acemoglu y Johnson (2003), Acemoglu y Robinson (2002) o Acemoglu, Johnson y Robinson (2001, 2002

\footnotetext{
${ }^{1}$ Véase en Gallup, Gaviria y Lora (2003) un análisis ponderado del efecto de diversos factores geográficos en el desarrollo de América Latina.
} 
y 2006) insisten en los patrones de asentamiento de los colonizadores como factor explicativo del tipo de instituciones — de propiedad privada o extractivas - que se crearon en las tierras conquistadas. En lugares donde los europeos no llegaron a establecerse por las insanas condiciones ambientales, en aquellos donde existía una abundante población que podía ser objeto de explotación directa, reclutamiento coercitivo o abusiva imposición o en donde había pocas riquezas que extraer, los europeos se despreocuparon de crear un sistema orientado a incrementar el bienestar agregado, implantando instituciones de tipo preferentemente extractivo. Por el contrario, allí donde la colonización se basó en la ocupación de espacios vírgenes y en la explotación de sus recursos, los propios colonizadores trataron de generar instituciones -en parte trasladadas de su país de origen- defensoras de la propiedad privada, que propiciaron el funcionamiento del mercado y alentaron el crecimiento. Las condiciones geográficas, especialmente las relacionadas con la persistencia de enfermedades endémicas, pudieron afectar también a las posibilidades de desarrollo, pero su influjo no sería directo, sino a través del modelo de colonización que propició: donde había alta prevalencia de enfermedades mortales, los europeos evitaron el asentamiento, generando, a cambio, instituciones de tipo extractivo que terminaron por dificultar el desarrollo.

Esta misma hipótesis ha servido para explicar los fenómenos de reversión de la fortuna. Es en las zonas más pobladas y urbanizadas —es decir, las más ricas en el momento de la colonización — donde se implantan instituciones predominantemente extractivas, lo que constituirá un obstáculo para su posterior desarrollo, mientras que, por el contrario, es en las zonas menos pobladas - más pobres en su origen - donde terminará por dominar la cultura de asentamiento que dará origen a la creación de instituciones de mercado, que son las que alientan su desarrollo posterior. La reversión de la fortuna es en realidad consecuencia de una "reversión de las instituciones".
La otra variante de este enfoque es la que sugieren Engerman y Sokoloff (1997, 2002, 2005 y 2006), quienes señalan que la dotación inicial de factores condiciona no sólo la distribución del ingreso, sino también las instituciones coherentes con ese patrón distributivo (Engerman, Haber y Sokoloff, 2000; Sokoloff y Engerman, 2000). Allí donde se dieron las condiciones para el desarrollo de la agricultura de plantación, con altas economías de escala y la posibilidad de emplear a mano de obra esclava (Brasil o el Caribe, por ejemplo), o donde la abundancia de mano de obra indígena permitía el recurso a métodos coercitivos de reclutamiento y explotación (México o el área andina), los patrones distributivos fueron altamente desiguales. En esos entornos se generaron instituciones excluyentes al servicio de una elite reducida y con limitada capacidad para generar resultados eficientes. Por el contrario, allí donde apenas existía población indígena y las condiciones eran más aptas para la explotación agraria familiar (ciertas partes de la costa este de los Estados Unidos, por ejemplo), se propiciaron instituciones más democráticas, interesadas en proveer bienes públicos, defender los derechos de propiedad y alentar las oportunidades económicas. Así pues, la dotación de factores condiciona la desigualdad social y el tipo de instituciones resultantes, y estas últimas, a su vez, influyen sobre las posibilidades de crecimiento.

Sea como resultado del modelo de asentamiento, sea como consecuencia de la dotación de factores previa, en ambos casos son las instituciones las que determinan la posterior senda de desarrollo. Instituciones que se ven condicionadas por los patrones distributivos vigentes $\mathrm{y}$ que a su vez condicionan esos patrones. En la medida en que América Latina se constituye en un referente básico para estos trabajos (especialmente para los de Engerman y Sokoloff), la hipótesis que sugieren aporta un buen punto de partida para la reflexión sobre la agenda de desarrollo de la región. No obstante, para derivar conclusiones es necesario previamente verificar la solidez de su propuesta.

\section{III}

\section{Historia sin "datos históricos"}

La explicación institucional del desarrollo ha logrado un eco notable tanto en los ambientes académicos como en el seno de los organismos internacionales. Especialmente, en estos últimos se ha convertido en la posición dominante desde la cual se interpretan las relaciones entre pobreza, instituciones y desarrollo, dando origen a lo que pareciera una "nueva ortodoxia" sobre el tema (Dobado, 2007). Ecos de esta posición pueden encontrarse en los dos estudios que el Banco Mundial dedicó al análisis de la desigualdad 
y su relación con el desarrollo en América Latina: Inequality in Latin America: Breaking with History? (De Ferranti, Perry y otros, 2004) y Poverty Reduction and Growth: Virtuos and Vicious Circles (Perry, Arias y otros, 2006). Esa misma posición subyace al Informe sobre el desarrollo mundial 2006: equidad y desarrollo (Banco Mundial, 2005).

Existen razones que podrían explicar la excelente acogida dispensada a la hipótesis institucional. En primer lugar, conecta con los fundamentos de la filosofía liberal anglosajona —de Locke, Smith o Stuart Mill—que subyace a buena parte de la doctrina económica y que insiste en el papel que el orden liberal y los derechos de propiedad tienen en los fundamentos del progreso. En segundo lugar, aleja la causa del subdesarrollo tanto del determinismo geográfico — que remite a factores ajenos al ser humano (como podría sugerir Diamond, 2005) — como del enfoque culturalista de tipo weberiano —que distingue entre buenos y malos colonizadores (por ejemplo, Landes, 1998). Frente a ambas posiciones, el enfoque institucional sitúa la causa del subdesarrollo en el marco social que moldea la conducta humana - las instituciones-, tratando de hacer endógena su explicación. Y es este esfuerzo por hacer endógenas las instituciones, apelando a procedimientos verdaderamente ingeniosos, uno de los méritos indudables de estas propuestas. Por último, de ellas emana una visión que conecta con los mensajes que los propios organismos internacionales están queriendo trasmitir acerca de la importancia que la calidad institucional y la cohesión social tienen en las estrategias de desarrollo de un país.

Ahora bien, más allá de su interés, las hipótesis sugeridas ¿están bien fundamentadas en la evidencia histórica? La respuesta no es enteramente favorable. Hay motivos para pensar que la apelación que realizan a la historia resulta insuficiente para fundamentar las tesis que quieren defender. El método de prueba, tanto para Acemoglu, Johnson y Robinson (en adelante AJR) como para Engerman y Sokoloff (en adelante ES), consistió en el recurso a los denominados "experimentos naturales" que surgen como consecuencia de las diversas experiencias de colonización. Como señalan Engerman y Solokoff (2006, p. 38), la historia de la colonización europea provee a los académicos con una rica colección de evidencias, un laboratorio que puede ser usado para estudiar el comportamiento económico y la evolución de las instituciones en el largo plazo. ${ }^{2}$ No obstante, los datos

\footnotetext{
${ }^{2}$ Las citas en letra cursiva corresponden a traducciones al español proporcionadas por el autor.
}

disponibles no son suficientes para la generalización que en ocasiones realizan, ni la información que manejan está en todos los casos libre de objeciones.

Las críticas pueden fundamentarse en el trabajo de los propios historiadores económicos (particularmente, latinoamericanistas), que realizan interpretaciones y aportan evidencias que resultan, al cabo, poco conformes con la interpretación de AJR y de Es. Los apartados siguientes pasan revista a los cuatro ámbitos a los que cabe referir la crítica.

\section{Excesiva generalización}

En primer lugar, es posible criticar la excesiva generalización en que incurren los trabajos aludidos, tanto de ES como de AJR. Esta crítica se desdobla en dos argumentos complementarios: por una parte, es difícil que un único factor causal dé cuenta de la diversidad de situaciones en la que se encuentran en la actualidad los países en desarrollo; por otra, ni siquiera los factores históricos con los que se ilustra la hipótesis pueden ser predicados de todos los países a los que se aplica.

Por lo que se refiere al primer aspecto, la pregunta relevante es si es posible interpretar las dispares sendas de desarrollo de los países a partir de una agregada e imprecisa definición de modelos de colonización. La división dicotómica entre instituciones extractivas y de propiedad privada ies suficiente para explicar la diversidad de situaciones existentes en el mundo en desarrollo? América Latina puede servir como ejemplo, ya que pocos sistemas coloniales generaron un marco institucional tan unificado y homogéneo como el español (Elliott, 2006). ¿Cómo es posible que un marco institucional común haya dado lugar a tal diversidad de resultados en términos de desarrollo? Piénsese que, como recuerda Coatsworth (2007), las diferencias de productividad entre las colonias latinoamericanas más ricas y más pobres eran, en 1800, casi tan grandes como las existentes entre las regiones más ricas y más pobres del mundo en su conjunto.

Por lo que se refiere al segundo aspecto, es muy dudoso que los rasgos con los que se definen los modelos de colonización sean generalizables al conjunto de los países afectados. Por ejemplo, es difícil atribuir al conjunto de América Latina un modelo de colonización basado en las instituciones extractivas, ni cabe aplicar al conjunto de los territorios del este de los Estados Unidos el predominio de instituciones de mercado (al modo de AJR). En el primer caso se encontrarían, cuando menos, las excepciones del Cono Sur latinoamericano, en el segundo los estados de Virginia y Carolina. ¿Por qué 
esa discrepancia no se manifestó en sendas de desarrollo claramente diferenciadas? Por lo demás, el modelo de colonización del Cono Sur, mucho más cercano al de la costa este de los Estados Unidos, debiera dar lugar - de acuerdo con Es- a instituciones democráticas e incluyentes, pero los niveles de desigualdad en Chile están entre los más altos de la región y los de Argentina o Uruguay, si bien inferiores, se encuentran en tramos igualmente elevados en términos internacionales.

Por lo demás, incluso países a los que se aplicó un modelo de explotación colonial relativamente similar, siguieron trayectorias de desarrollo manifiestamente dispares, contradiciendo los supuestos de AJR y ES. Es el caso, por ejemplo, de Cuba y Brasil, a los que se aplicó un modelo de colonización semejante, basado en el predominio de la plantación y del trabajo esclavista, pero mientras uno - Cuba- se encontraba entre las sociedades más ricas de América Latina a comienzos del siglo XIX, el otro - Brasil- ocupaba los tramos más bajos de esa jerarquía. Y qué decir de los países centroamericanos, como Guatemala o Nicaragua, economías de bajo nivel de ingreso y alta desigualdad, pero cuyo modelo de colonización difícilmente puede acomodarse al predominio de la plantación esclavista o a la presencia de minería compulsiva propios de las instituciones extractivas.

\section{Ausencia de datos históricos}

Uno de los rasgos que caracterizan a la interpretación institucional es el recurso que hace a la historia para fundamentar las causas últimas del subdesarrollo. Se trata de una apelación genérica, pero carente de "hechos históricos": en las interpretaciones de AJR y de ES apenas existen datos históricos, análisis de secuencia o estudio detenido de contextos. Se trata de interpretaciones magnas, de "narrativas metahistóricas" (Coatsworth, 2007, p. 2), construidas con una muy limitada base empírica que en el mejor de los casos sugiere, más que demuestra, las hipótesis que se quieren defender. Como señala Dobado (2007) "la historia económica de Iberoamérica, o de otras ex-colonias, apenas está presente ni en los trabajos de Engerman-Sokoloff, ni en los de Acemoglu-JohnsonRobinson. Basta a este respecto con echar una ojeada a las bibliografías que acompañan sus trabajos".

Esta carencia pesaría menos si las interpretaciones ofrecidas por AJR y ES se apoyasen en las evidencias e interpretaciones aportadas por los estudios históricos sobre la región. Pero no parece que este sea siempre el caso. Para empezar porque, como se ha señalado, los autores parecen haber hecho muy poca consulta de las investigaciones realizadas por los especialistas en historia económica y no han sustituido esa carencia con la aportación de evidencia emanada de un trabajo propio de reconstrucción histórica. Pero, además, porque dan por supuesta una realidad que, en muchos casos, los estudios históricos han impugnado. Más adelante se volverá sobre este tema, pero baste ahora con señalar el uso que AJR hacen de la presencia de abundante población indígena como factor que explica la implantación de un modelo de colonización extractivo en México o en el área andina. ¿Puede sostenerse ese argumento sin alteración aun a sabiendas de que en apenas un siglo desapareció el 90\% de la población local? ¿La catástrofe demográfica que sucedió a la primera implantación europea no afectó al tipo de instituciones propias de la colonización? (Dobado, 2007).

\section{Excesiva confianza en la trayectoria}

Una de las aportaciones positivas de la tesis institucionalista es su reivindicación de la secuencia temporal, de la inercia histórica. Como señalan Banerjee e Iyes (2002, p. 1): En la nueva visión institucionalista, la historia importa porque la historia influye en las instituciones y estas influyen en la economía.

Ciertamente, es difícil entender muchos de los obstáculos al desarrollo sin apelar a los procesos históricos en los que estos se gestan. Ahora bien, resulta excesivo suponer que la explicación del atraso necesariamente deba remitirse al momento de la colonización. Tienen razón Przeworski y Curvale (2005, p. 2) cuando argumentan que la tesis institucionalista que se mira "es el espejo de la teoría de la dependencia", si bien en este caso son las instituciones, modeladas en su día por las potencias coloniales, las que determinan la clave del desarrollo.

En el caso de regiones como América Latina, ese planteamiento supone remitir la explicación de las insuficiencias del presente a cinco siglos atrás en la historia. ¿No ha pasado nada importante desde entonces? Resulta sorprendente, por cuanto entremedio se han producido hechos tan relevantes para la historia de la región como: i) la independencia, que supuso un punto de ruptura clave en los modelos de inserción internacional, en la estructura y dinámica sociales y en la configuración de las instituciones propias de estos países; ii) la revolución de los transportes de mediados del siglo XIX, que redujo las potenciales economías de aglomeración, cuando América Latina todavía no había iniciado su industrialización; iii) el alza de los precios de las materias primas en el período de entre siglos, que acentuó la especialización 
primario-exportadora de la región; iv) la política de industrialización dirigida por el Estado de la segunda mitad del siglo XX, que si bien impulsó las capacidades manufactureras, alentó desequilibrios importantes en la conducción económica de los países y, finalmente, v) la crisis de la deuda y las reformas económicas de los años 1980, con su influencia en el cambio de orientación de la política económica. Se trata de acontecimientos importantes en la historia económica en la región, pero a los efectos de la tesis que se analiza no merecen siquiera consideración.

\section{Interpretación objetable}

La limitada atención a la investigación histórica y el gusto por la generalización se traducen, en los casos de AJR y ES, en una interpretación de los datos históricos que difícilmente coinciden con los que emanan de los estudios especializados. No es posible hacer aquí una relación exhaustiva de las inconsistencias, baste como muestra representativa las siguientes:

i) No es claro que el retraso de América Latina pueda situarse en el momento al que lo remiten AJR y ES. Coatsworth (2005, p. 8) lo sitúa muy posteriormente, en el entorno del ciclo independentista: Latinoamérica no fue subdesarrollada de acuerdo a ninguna medida convencional (como el PIB per cápita) hasta algún momento entre aproximadamente 1750 y 1850"; a ese mismo período - siglo XIX — remite también Haber (1997) el comienzo del atraso latinoamericano; en igual sentido se pronuncia Bulmer-Thomas (1994); por su parte, Prados de la Escosura (2005), al comparar la región no con los Estados Unidos sino con el resto de la Organización de Cooperación y Desarrollo Económicos (OCDE), lo retrasa casi un siglo más: El retardo de América Latina, en relación a otros países, parece ser un producto del siglo XX.

ii) La importancia que otorgan a la encomienda como ejemplo de institución extractiva implantada en América Latina parece contradecirse con el probado retroceso que esa figura tuvo a partir del siglo XVII (Carmagnani, 2004); y tampoco el modelo de la hacienda puede generalizarse como forma dominante de explotación agraria en América Latina (Miño, 1991).

iii) Frente a lo que dan a entender ES, no parece que el recurso al trabajo coercitivo en las minas haya sido un procedimiento habitual de reclutamiento laboral, salvo quizá en las primeras etapas de la colonización (Velasco, Flores y otros, 1988) e, incluso, datos referidos a México sugieren que los salarios en las minas eran relativamente elevados, negando la idea de unas condiciones laborales y de retribución próximas a la esclavitud (Dobado, 2007).

iv) No parece que la colonización hispana haya dado la espalda a la regulación del derecho de propiedad y nada indica que hayan existido restricciones normativas que impidiesen el acceso de la población indígena a la propiedad tanto de la tierra como de las minas (Dobado, 2007).

v) La imagen que transmiten de una sociedad colonial altamente polarizada, si bien tiene cierta parte de verdad, no da cuenta de la existencia de una clase media - y mestiza- que alcanzó en algunos casos cierta significación (Carmagnani, 2004); los datos disponibles parecen sugerir que los comparativamente elevados niveles de desigualdad en América Latina son más un producto del periodo posterior al siglo XIX que una consecuencia inmediata de la colonización (Coatsworth, 2005; Williamson, 1999).

vi) Finalmente, el estudio comparado de la evolución de los marcos institucionales de España y de América Latina sugieren similitudes que no se corresponden ni con la dotación de factores respectiva, ni con la distribución del ingreso existente en cada caso, negando de este modo la tesis de Es (Coatsworth y Tortella, 2002).

De todos estos factores, parece de especial relevancia la ausencia de confirmación de los anómalos niveles de desigualdad de América Latina en la inmediata poscolonización, ya que se trata de un supuesto básico en la argumentación de Es (sobre el que, por cierto, no aportan información alguna). Los datos parecen sugerir que la desigualdad en la América hispana, si bien elevada, no era superior a la de otras regiones que, sin embargo, experimentaron procesos de industrialización exitosa (Coatsworth, 2005). Por ejemplo, de acuerdo con los datos de Bourguignon y Morrison (2002), en 1820 el nivel de desigualdad de México era similar al del Reino Unido; Williamson (1999), a través de la razón salario-renta de las tierras, confirma que el incremento más acusado en la desigualdad se produjo en las décadas previas a la primera guerra mundial; Gelman (2007) sugiere que buena parte del actual nivel de desigualdad de Argentina es un producto posterior al último tercio del siglo XIX, y lo mismo parece aplicarse a Uruguay, según sugieren los estudios de Bértola Flores (2005).

Por lo demás, la impresión que emana de estos estudios no se refiere solo a la distribución del ingreso, sino a la del activo más importante del momento: la tierra. Coatsworth (2005, p. 139), por ejemplo, señala 
que la propiedad de la tierra (y de la riqueza más en general) estaba no más concentrada en Latinoamérica que en las trece colonias británicas (o en la propia e industrializada Gran Bretaña). Lo que explica que dicho autor concluya: "La tesis de Engerman y Sokoloff, aunque plausible, es casi ciertamente errónea".

\section{IV}

\section{¿De qué instituciones se habla?}

Si la hipótesis institucional se caracteriza por hacer una apelación a la historia sin apenas recurrir al escrutinio histórico, de igual modo cabe reprocharle que apunte a la relevancia de las instituciones sin apenas definir qué entiende por instituciones, ni cómo proceder a crear el marco institucional supuestamente necesario para promover el desarrollo. Dado el intenso debate que existe al respecto, no se trata de una carencia menor.

En efecto, ni AJR ni Es dedican esfuerzo analítico alguno a explicitar el concepto de instituciones que subyace a su argumentación y son más bien genéricas e imprecisas las referencias que AJR realizan a los dos tipos de instituciones —extractivas y de mercado- sobre las que, centralmente, descansa su hipótesis explicativa. ¿Qué características debe tener una institución para que sea considerada extractiva o de mercado? Es un interrogante para el que no hay una respuesta precisa.

Pese a su silencio, es posible derivar algunos supuestos doctrinales discutibles que subyacen, a veces de forma implícita, a las posiciones de AJR y ES. En concreto, por señalar los más centrales: i) entienden por instituciones el marco formal que define el conjunto de restricciones en el que operan los agentes; ii) suponen que es posible delimitar a priori y con carácter universal un marco de instituciones óptimo (o cuando menos adecuado) para promover el desarrollo (son las llamadas, pero no definidas, instituciones de mercado), y iii) ese marco está compuesto centralmente por las instituciones relacionadas con la defensa de los derechos de propiedad y con las que garantizan fórmulas democráticas de gobierno (a estas se añaden las referidas a la provisión de bienes públicos, en especial relacionadas con la formación de recursos humanos).

Esta concepción del marco institucional resulta manifiestamente limitada. En especial hay dos problemas no considerados por AJR y ES que resultan de notable significación para interpretar el proceso de desarrollo: la relevancia de las instituciones informales y el carácter predominantemente contingente del marco institucional. Veamos ambos aspectos de forma breve.

\section{Instituciones formales e informales}

El primero de los problemas alude a la desconsideración que AJR y Es hacen del papel que tienen, en la vida económica y social, las instituciones informales: es decir, aquellas que no tienen una definición expresa y que se fundamentan no tanto en leyes o en normas explícitas cuanto en creencias, tradiciones y culturas. Se trata de dos tipos de instituciones diferentes: mientras que las instituciones formales están abiertas al escrutinio público y proveen un marco de incentivos (y penalizaciones) reconocible para el conjunto de la sociedad, las instituciones informales son más difíciles de identificar, en parte porque sus estímulos (y penalizaciones) son menos expresos y en parte porque pueden ser respuestas altamente específicas a las condiciones de un determinado grupo social (y no del conjunto de la sociedad). Mientras las primeras se asientan sobre relaciones impersonales, dando origen a marcos preferentemente universales (o multilaterales) de acuerdo, las segundas suelen ser más interpersonales, más tácitas y basadas en la costumbre. El proceso histórico de modernización de las sociedades y el progresivo dominio del mercado suelen conducir a una progresiva sustitución de las instituciones informales por aquellas que tienen una existencia explícita y formal. Así, por ejemplo, las formas de propiedad tradicional, asentadas en la memoria local, abren paso a los sistemas de registro oficial de la propiedad; y las formas de trabajo comunal, basadas en el acuerdo o la costumbre, se sustituyen por contratos laborales explícitos. Es en las economías más tradicionales y en las sociedades más fragmentadas donde el marco de instituciones informales adquiere mayor relevancia.

De hecho, en una economía poco mercantilizada (como sucede en los países más pobres o en los sectores agrícolas de esos países) este tipo de instituciones informales pueden ser relativamente eficientes, ya que se basan en la costumbre y en el conocimiento y la confianza entre los agentes implicados. De este modo, reducen notablemente los costes de transacción, pero a costa de limitar la expansión del mercado y la profundización 
de la especialización productiva. A medida que el círculo de relaciones entre los agentes se amplía, se abre mayor espacio al comportamiento oportunista. Como consecuencia, los costes de transacción se elevan, siendo necesario apelar en mayor medida a reglas formales y multilaterales de carácter impersonal (Bardhan, 2005). Este proceso fue estudiado por Greif (1994 y 2004) en relación con las garantías contractuales para el comercio a distancia de genoveses y maghrebíes en los siglos XV y XVI (Greif, Milgrom y Weingast, 1994).

Ahora bien, no solo importa la reducción que las instituciones motivan en los costes de transacción, sino también su capacidad para propiciar el cambio social y adaptarse a los nuevos requerimientos de una realidad cambiante. También en este ámbito suelen ser mayores las ventajas de las instituciones formales sobre las informales. Mientras las primeras son más transparentes y abiertas a la crítica, las segundas son más opacas e inerciales y, por su especificidad, suelen dificultar la movilidad social. Como señala North (2005, p. 157), mientras las instituciones formales pueden ser alteradas por una decisión, las instituciones informales no son fácilmente influenciables por un cambio deliberado de corto plazo y sus características de "enforcement" son solo muy imperfectamente sujetas a control deliberado.

En suma, el proceso de creciente mercantilización de las sociedades — su proceso de desarrollo— aparece acompañado de una progresiva extinción de las instituciones informales (y comunales) y su sustitución por mecanismos más formales (y universales). A través de ese proceso se abre mayor espacio al cambio social, mejorando la "eficiencia adaptativa" de las instituciones. Porque lo importante, como señala North (2005), no es tanto obtener una respuesta institucional eficiente en un momento dado, cuanto garantizar la capacidad de adaptación del marco institucional a la cambiante realidad económica; y la capacidad de cambio de las instituciones formales es muy superior a la de las instituciones informales. Desde esta perspectiva, la progresiva formalización del marco institucional no es solo un producto del desarrollo, sino también un factor que puede contribuir a estimular ese mismo proceso, $y$, por el contrario, la dominante permanencia de instituciones informales en una sociedad podría verse como un potencial obstáculo al cambio. En ocasiones, incluso, estas se conforman como un mecanismo de resistencia de ciertos colectivos frente a un entorno que entienden como ajeno, por ello no es extraño que la informalidad domine en sociedades altamente fragmentadas. Una observación que es pertinente para el caso de América Latina (Perry, Maloney y otros, 2007).
Por lo demás, la eficacia de las instituciones formales puede verse alterada por la subterránea persistencia de instituciones informales con alta capacidad para hacer cumplir sus decisiones. Como es sabido, una institución existe si es capaz de modular la conducta social, generando comportamientos previsibles en los individuos (North, 1990). No obstante, la condición para que una institución genere comportamientos regulares es que sea concebida como un sistema que promueve la identificación de los individuos con los comportamientos que se esperan del marco de incentivos que el sistema define, dando lugar a una estructura endógena o autosostenida. Dicho de otro modo, una norma que no se cumple (y nadie espera que se cumpla) no constituye una institución, por más que tome cuerpo en una ley o en una organización. Por ello, tan importante es analizar las reglas existentes como las motivaciones que los individuos tienen para cumplirlas. Es posible que en aquellos casos en que se ha pretendido trasplantar una estructura institucional formal y sobreponerla a otra previamente existente (de carácter informal), el resultado sea ineficiente, al ser incapaz aquella de moldear de forma efectiva las conductas sociales. Una observación que explica el limitado éxito que han tenido las fórmulas de "trasplante institucional", replicando en un país en desarrollo una respuesta institucional supuestamente eficiente en un país desarrollado. Incluso, es muy posible que la imposición lleve aparejada la revitalización de las instituciones informales como marco de reclusión de grupos que se sienten amenazados por el nuevo marco institucional, obstaculizando con ello los procesos de movilidad y de cambio social.

Tomando en consideración estos aspectos podría ofrecerse una interpretación alternativa a la sugerida por AJR y ES. Podría sugerirse que en los países donde se practicó una "colonización de la tierra" (asentamiento sobre tierras vírgenes) debieron dominar las instituciones formales (en parte, trasplantadas de Europa), lo que les preparó mejor para la movilidad y el cambio social, de acuerdo con los cambiantes incentivos del mercado. Por su parte, en los países donde se practicó una "colonización de personas" (con importantes colectivos de poblaciones indígenas) las instituciones formales se solaparon (a veces, en conflicto) con las instituciones informales previas, alentando la fragmentación social y dificultando los procesos de movilidad y cambio social que el dominio del mercado exige. Conforme a esta interpretación, la causa del atraso económico podría estar no tanto en las instituciones coloniales en sí, cuanto en la resistencia de las instituciones informales al cambio, en un marco de desarticulación social motivado por la propia colonización. 
No es fácil disponer de información acerca del tejido de instituciones informales; y menos si se refieren a períodos precedentes en la historia. La fragmentación social (étnica o lingüística) puede ser un buen candidato para medir este fenómeno. La perdurabilidad de esos tipos de fragmentación social puede constituir variables que expresen la mayor presencia de instituciones informales. Lo cierto es que se aprecia una relación negativa entre grado de fragmentación lingüística y ética (tomada de Alesina, Devleeschauwer y otros, 2003) y nivel de desarrollo medido a través del PIB per cápita del 2004, a paridad de poder adquisitivo (gráfico 1).

GRÁFICO 1

Fragmentación lingüística y ética y nivel de desarrollo
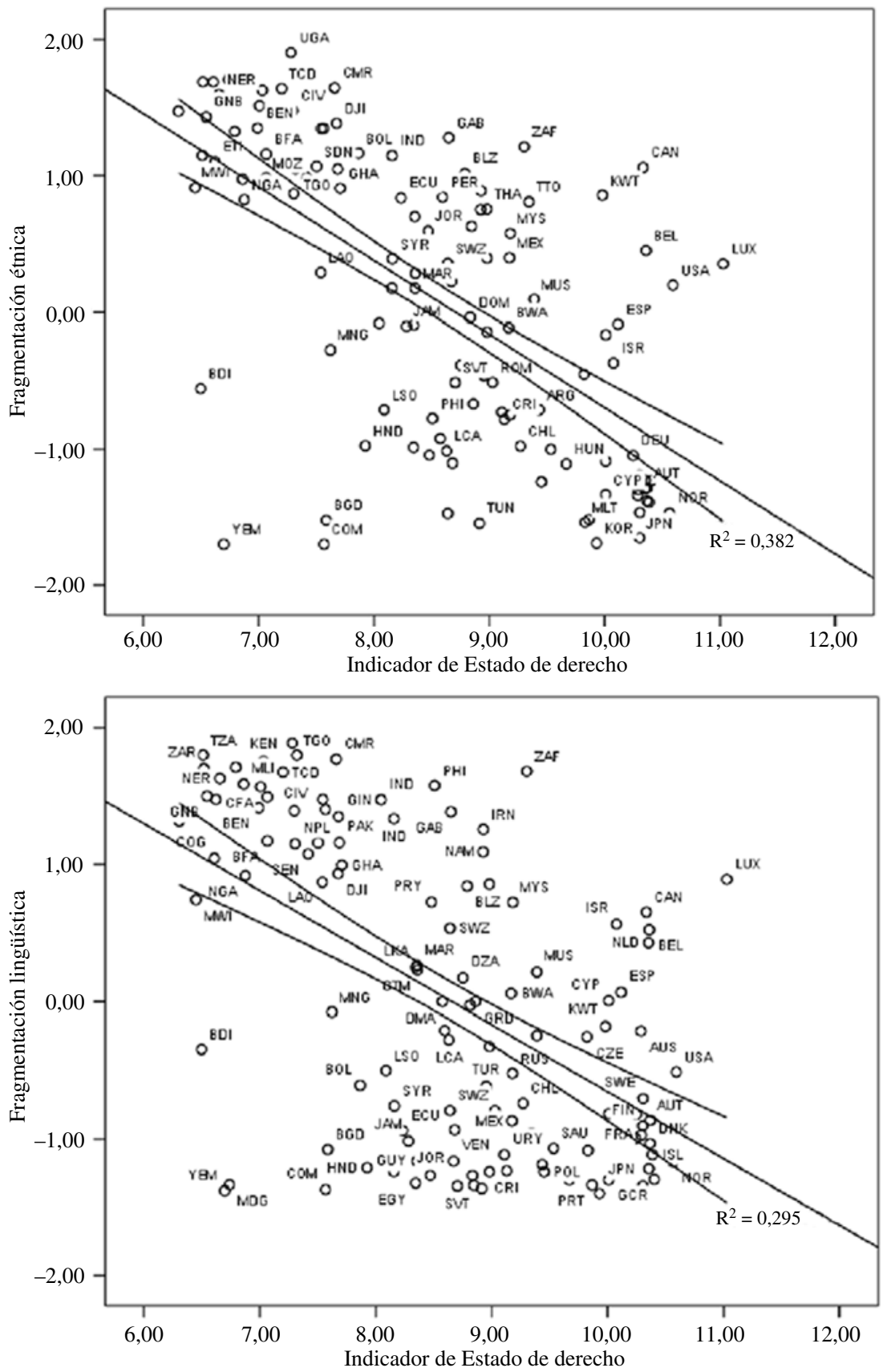

Fuente: elaboración propia con datos del Banco Mundial (2006), y de Alesina, Devleeschauwer y otros (2003). 
De acuerdo con lo señalado, es probable que las instituciones formales operen con menor eficacia en aquellos contextos sociales de alta informalidad (aproximada a través de la fragmentación social). Como muestra el gráfico 2, aunque el vínculo es menos claro, también se aprecia una relación negativa entre fragmentación ética

Fragmentación ética y lingüística y calidad institucional

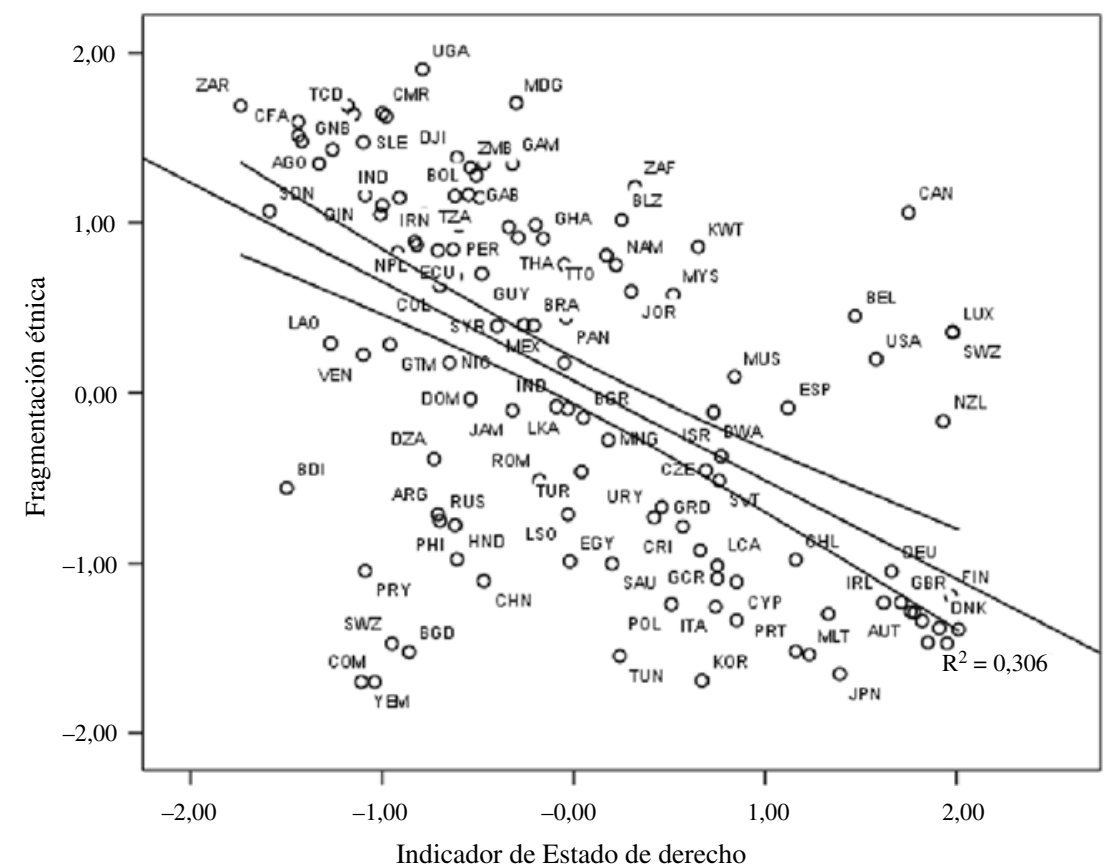

Indicador de Estado de derecho

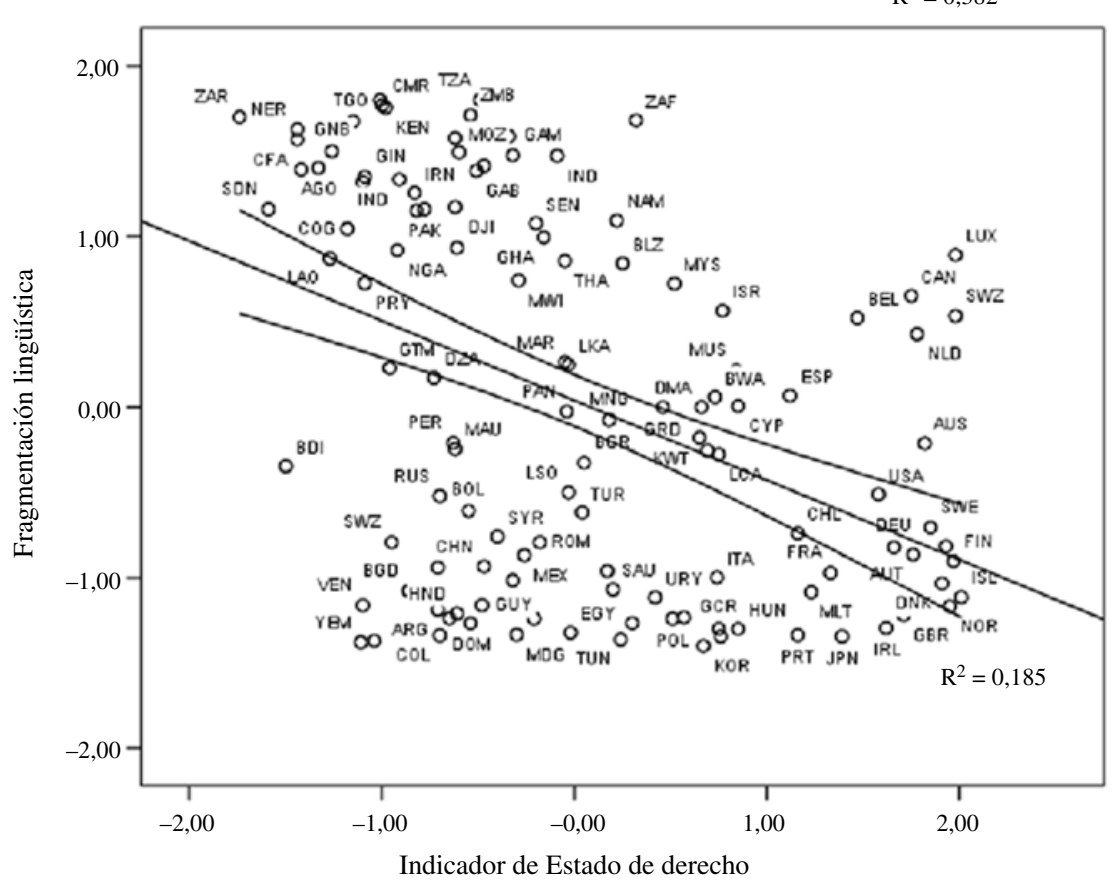

Fuente: elaboración propia con datos del Banco Mundial (2006) y de Kaufmann, Kraay y Mastruzzi (2005). 
y lingüística y calidad institucional (aproximada a través del indicador de Estado de derecho, EDER) ${ }^{3}$.

\section{2. ¿Existen instituciones óptimas?}

El segundo problema de la interpretación de AJR y ES alude al dudoso supuesto de que es posible definir un marco institucional óptimo sin referencia al contexto social propio de cada país. La existencia de múltiples equilibrios, la complementariedad de las instituciones y el hecho de que una misma institución pueda desempeñar diversas funciones hace que sea difícil definir una respuesta institucional óptima universal a un problema dado. Incluso, aun cuando pueda existir consenso acerca de la política económica deseable, el rango de opciones institucionales para lograr ese objetivo puede ser dilatado. No quiere decirse con ello que toda respuesta institucional pueda ser válida o que no quepa evaluar opciones alternativas, sino que existen diversas respuestas posibles — todas igualmente aceptables- para determinados contextos. Lo que subraya la importancia de las condiciones locales como determinantes básicos de la adecuación de una institución (Islam y Montenegro, 2002).

La relativa especificidad de las instituciones es lo que explica la eficacia relativa de lo que se ha denominado instituciones de transición (Quian, 2003): fórmulas destinadas a adaptar el marco institucional vigente a cambios en el entorno, que no responden a las fórmulas canónicas de las instituciones supuestamente óptimas, pero que permiten corregir ineficiencias a través de un proceso dinámico y altamente específico. Probablemente, desde una perspectiva abstracta cabría considerar a estas respuestas institucionales como ineficientes, pero en realidad son vías de transición que resultan adaptadas a las condiciones locales y generadoras de procesos de cambio consistentes con los objetivos de desarrollo. Aquí merece la pena recordar el principio de "remediabilidad" del cambio institucional al que alude Williamson (1985): una respuesta institucional no puede considerarse ineficiente a menos que exista una alternativa superior que sea socialmente viable. Lo que planteado de otra forma diría que no cabe definir la eficiencia de una institución a partir de un diseño supuestamente universal, sino en referencia con la mejor de las posibilidades alternativas socialmente factibles.

Por ejemplo, nadie sugeriría que China constituye un ejemplo de sociedad liberal y defensora de los derechos de propiedad (las dos dimensiones del marco institucional más valoradas por AJR); sin embargo, China está creciendo a tasas medias cercanas al $7 \%$ de su producto interno bruto (PIB) per cápita desde hace más de dos lustros. ¿Qué sucede? ¿Es una economía de éxito encerrada en un marco institucional ineficiente? Probablemente, lo que sucede es que ese país está generando respuestas institucionales altamente específicas, supuestamente ineficientes si se comparan con el patrón ideal de una economía de mercado, pero altamente dinamizadoras del cambio en el contexto específico de la realidad social china. En ese sentido, las respuestas institucionales han sido concordantes con el principio de eficiencia adaptativa mencionado más atrás.

En suma, es posible que las instituciones formales implantadas en el Nuevo Mundo hispano hayan sido ineficientes, pero ese juicio no puede derivarse de su mero contraste con un modelo óptimo universal, sino con el estudio de las condiciones sociales específicas de las sociedades implicadas. No parece que resulte desaconsejable, por tanto, una mirada más detenida a la historia para tratar de identificar la adecuación de las respuestas institucionales y su inercia en el tiempo.

\section{V}

\section{Prueba empírica de la importancia}

\section{de las instituciones}

Los anteriores planteamientos podrían trasladarse, aunque solo sea de manera tentativa, a un modelo empírico que entable diálogo con los hasta aquí considerados. Tratando

\footnotetext{
${ }^{3}$ Dicho indicador aparece en una publicación del Banco Mundial y fue elaborado por Kaufmann, Kraay y Mastruzzi, (2005).
}

de simplificar las opciones, tres son las alternativas básicas hasta ahora ofrecidas para explicar el nivel de desarrollo de los países: i) Gallup, Sachs y Mellinger (1998) y Sachs (2001) insisten en el peso que tienen los factores geográficos (especialmente la salida al mar y la distancia a los trópicos); ii) Acemoglu, Johnson 
y Robinson (2002) subrayan la importancia que cabe atribuir a las instituciones, condicionadas por el modelo de colonización del país, y iii) Rodrik, Subramanian y Trebbi (2002) añaden a esos dos factores el potencial efecto positivo del comercio, medido a través del grado de apertura comercial. No obstante, pese a apelar a la variable instrumental construida por Frankel y Romer (1999), la apertura comercial en este último trabajo no resulta significativa (y aparece con signo negativo).

Al igual que hicieron Rodrik, Subramanian y Trebbi (2002), partiremos de suponer que el nivel de desarrollo de un país puede estar influido por la geografía (medida por la distancia a los trópicos), por la calidad de las instituciones (medida por el indicador del Estado de derecho construido por Kaufmann, Kraay y Mastruzzi) y por la integración comercial (medida por el grado de apertura). No obstante, el problema es que estas dos últimas variables (calidad institucional e integración comercial) son endógenas, ya que pueden estar influidas por el nivel de desarrollo del país, lo que hace necesario definir los instrumentos adecuados para la estimación.

A este respecto, y en relación con estudios previos, se insistirá aquí en la importancia que para las posibilidades de desarrollo de un país tienen la dimensión y accesibilidad del mercado interno y del internacional próximo. La dimensión de los mercados condiciona el grado de profundidad de la especialización productiva y, en su caso, de aprovechamiento de economías de escala que están implícitas en el proceso de industrialización; por su parte, la accesibilidad, medida por la inversa de la distancia, aproxima los costes para el intercambio. Con el fin de transformar este factor en un instrumento adecuado para la estimación, se aproxima la dimensión de un mercado a través de la población de los núcleos urbanos, ya que se entiende que es en las ciudades donde se concentran las actividades mercantiles de un país. La población considerada es la de 1890 , por entender que es entonces cuando se abre el arco de distribución del ingreso a escala internacional. Es decir, al igual que en los modelos de gravitación, el indicador de la atracción de mercado vendría dado por $\sum \operatorname{Ln} \frac{P_{i} P_{j}}{L_{i j}}$, donde $P$ indica la población en 1890, $i$ y $j$ los núcleos urbanos considerados y $L$ la distancia entre ambos.

Esta fórmula se aplicó tanto al mercado interno como al internacional, si bien con criterios distintos. En concreto, en el caso del mercado interno, se analizó el conjunto de las ciudades que en 1870 tenían más de 30.000 habitantes, considerando como distancia la que media entre cada núcleo urbano y la capital del país. Así pues, cuanto más urbanizado esté el país y menor sea la distancia entre los núcleos urbanos, mayor será la dimensión efectiva del mercado interno. A su vez, para medir la dimensión de los mercados internacionales se tomó en cuenta la población solo de las capitales de aquellos países que se encuentran en un radio máximo de 3.000 kilómetros, que es lo que conforma, de forma razonable, un mercado regional relativamente próximo.

Pues bien, se considera que la variable alusiva a la integración comercial aparecerá condicionada por tres factores: en primer lugar, en sentido negativo, por la dimensión del mercado nacional, ya que la existencia de un mercado interno amplio hace menos necesario recurrir al intercambio internacional; en segundo lugar, y también de forma negativa, por el tamaño del país - medido a través del logaritmo de la población-, ya que este afecta a la medición de la apertura y, por último, con signo positivo, por la dimensión del mercado internacional próximo, que facilita los intercambios y mejora las posibilidades de inserción internacional.

Por lo que se refiere a la calidad de las instituciones, esta viene condicionada por diversos factores. En primer lugar, en sentido negativo, por el nivel de fragmentación de la sociedad, que refuerza el recurso de los agentes a instituciones informales, aminorando la eficacia (y, en ocasiones, la credibilidad) del sistema institucional de carácter formal. La fragmentación social se aproxima a través de dos variables alternativas, de resultados muy próximos: la fragmentación lingüística y la fragmentación étnica (las dos obtenidas de Alesina, Devleeschauwer y otros, 2003). Ambas variables expresan la probabilidad de que dos individuos de un país tomados al azar hablen lenguas distintas o tengan origen étnico diferente. En segundo lugar, la calidad institucional puede estar influida también por la ubicación del país, medida por la distancia respecto a los trópicos. Las circunstancias ambientales de los trópicos afectan adversamente las condiciones de salud de las personas y los niveles de productividad de los suelos agrícolas, haciendo más difícil la articulación social y la calidad institucional. En tercer lugar, el tamaño de la población también puede repercutir, en sentido negativo, sobre la calidad de las instituciones, ya que siendo todo lo demás igual, resulta más fácil configurar instituciones eficaces y creíbles en países de limitada dimensión. Por último, el tamaño del mercado nacional puede operar en sentido positivo sobre la calidad de las instituciones, por cuanto está relacionado, hasta cierto punto, con el nivel de urbanización del país. 
Los resultados de la estimación que se ha realizado por mínimos cuadrados ordinarios en dos etapas (variables instrumentales) sugieren que la explicación del nivel de desarrollo descansa básicamente sobre la variable institucional (cuadro 1). En este sentido refuerzan la interpretación de Rodrik, Subramanian y Trebbi
(2002) y las sugerencias de AJR y Es. Como en dicho trabajo, la variable referida a la integración comercial no resulta significativa y aparece con el signo inverso. Por su parte, la variable alusiva a la geografía opera con el signo adecuado y está al borde de ser significativa. No obstante, las condiciones geográficas influyen también,

CUADRO 1

Factores determinantes del desarrolloa

\begin{tabular}{|c|c|c|c|}
\hline \multirow{3}{*}{$\frac{\mathrm{N}^{\circ} \text { de observaciones: } 125}{\text { Instituciones (Estado de derecho: EDER) }}$} & \multicolumn{3}{|c|}{$\begin{array}{l}\text { Logaritmo del PIB per cápita a paridad } \\
\text { de poder adquisitivo, } 2004\end{array}$} \\
\hline & \multicolumn{3}{|c|}{ Dos etapas (variables instrumentales) } \\
\hline & $\begin{array}{c}0,975 \\
(6,829)\end{array}$ & & $\begin{array}{c}0,995 \\
(6,718)\end{array}$ \\
\hline Comercio (apertura comercial: LNTR) & $\begin{array}{l}-0,119 \\
(-0,614)\end{array}$ & & $\begin{array}{l}-0,197 \\
(-1,035)\end{array}$ \\
\hline Geografía (distancia al trópico: LATAB) & $\begin{array}{c}0,009 \\
(1,627)\end{array}$ & & $\begin{array}{c}0,008 \\
(1,493)\end{array}$ \\
\hline \multirow[t]{3}{*}{$\begin{array}{l}\mathrm{R}^{2} \\
\mathrm{R}^{2} \text { ajustado }\end{array}$} & $\begin{array}{l}0,668 \\
0,660\end{array}$ & & $\begin{array}{l}0,679 \\
0,671\end{array}$ \\
\hline & \multicolumn{3}{|c|}{ Primera etapa para variables endógenas } \\
\hline & EDER & EDER & LNTR \\
\hline Fragmentación lingüística (FLEN) & $\begin{array}{l}-0,183 \\
(-2,536)\end{array}$ & & \\
\hline Fragmentación étnica (FETN) & & $\begin{array}{l}-0,265 \\
(-3,151)\end{array}$ & \\
\hline Población (LPOB) & $\begin{array}{l}-0,173 \\
(-4,033)\end{array}$ & $\begin{array}{l}-0,173 \\
(-4,033)\end{array}$ & $\begin{array}{l}-0,143 \\
(-6,522)\end{array}$ \\
\hline Dimensión del mercado nacional (DMN) & $\begin{array}{c}0,225 \\
(3,390)\end{array}$ & $\begin{array}{c}0,215 \\
(3,279)\end{array}$ & $\begin{array}{l}-0,058 \\
(-1,762)\end{array}$ \\
\hline Dimensión del mercado regional (DMR) & & & $\begin{array}{c}0,085 \\
(2,630)\end{array}$ \\
\hline Geografía (LATAB) & $\begin{array}{c}0,023 \\
(5,485)\end{array}$ & $\begin{array}{c}0,019 \\
(4,036)\end{array}$ & \\
\hline $\mathrm{R}^{2}$ & 0,429 & 0,445 & 0,404 \\
\hline $\mathrm{R}^{2}$ ajustado & 0,410 & 0,426 & 0,389 \\
\hline
\end{tabular}

Fuente: elaboración propia.

a La variable que expresa el nivel de desarrollo es el PIB per cápita del 2004, a paridad de poder adquisitivo (Banco Mundial); la variable alusiva a la calidad institucional (EDER) es el indicador que expresa el Estado de derecho entre los indicadores de gobernabilidad de Kaufmann, Kraay y Matruzzi (2005); la integración comercial se expresa a través del coeficiente de apertura (exportaciones más importaciones sobre el PIB); la variable geográfica se mide como latitud en términos absolutos dividido por 90; la fragmentación étnica y la fragmentación lingüística están tomadas de Alesina, Devleeschauwer y otros (2003). La población es la de 2004 (Banco Mundial); la dimensión del mercado nacional se construye a partir de todas las ciudades del país que en 1890 tenían más de 30.000 habitantes y la distancia que las separa de su capital, a partir de la siguiente fórmula $\sum_{i=1}^{n} \operatorname{Ln}\left[\left(p_{i}^{*} p_{i}\right) / d\right]$, donde $p_{c}$ es la población de la capital en $1890, p_{i}$ es la población de las ciudades con más de 30.000 habitantes en 1900, y $d$ es la distancia existente entre la capital y dicha ciudad; la dimensión del mercado regional se estima mediante la aplicación de la misma fórmula a la población de las capitales de todos los países localizados en un entorno de 3.000 km y a la distancia existente entre ellas. 
y de manera apreciable, en la calidad institucional, tal como se suponía en el modelo. Por lo demás, es destacable la capacidad explicativa de las variables construidas para medir la capacidad de atracción de los mercados nacional y regional, que operan tanto sobre el nivel de apertura de la economía como sobre el nivel de calidad de las instituciones.

Conforme a los resultados de la estimación, la geografía y las instituciones influyen en las posibilidades de desarrollo de los países. Pero la calidad de las instituciones no viene condicionada necesariamente por los modelos de colonización de los países, sino por la fragmentación social sobre la que esas instituciones se erigen. En entornos de elevada fragmentación social, las instituciones son de peor calidad, en gran medida porque es posible que subsista una red fragmentada de instituciones informales. Al mismo tiempo, la eventual presencia de una red de núcleos urbanos próximos sobre los cuales asentar el mercado condiciona tanto las po- sibilidades de inserción internacional como la calidad institucional. En este segundo caso influye la red de ciudades existente en el seno del país, que además de expresar la dimensión del mercado local, aproxima el nivel de urbanización. En el caso de la inserción internacional, lo que importa es la ubicación del país en un entorno regional amplio y accesible.

Más allá de las hipótesis respaldadas por este ejercicio empírico, permanecen las preguntas referidas a cómo cada país aprovechó las posibilidades que le brindaba cada uno de los factores aquí considerados. Por ejemplo, qué hizo que Australia venciese su limitada disponibilidad de mercados regionales y que, en cambio, Marruecos no hubiese aprovechado esa ventaja relativa; o por qué Canadá vence su relativamente elevada fragmentación lingüística $y$, en cambio, Madagascar no se ha beneficiado de su mayor homogeneidad. Son preguntas que interpelan a las aportaciones de la investigación histórica, necesariamente referidas al estudio de las particularidades de cada caso.

\section{VI}

\section{La desigualdad, las instituciones y el agua de la bañera}

\section{Desigualdad e instituciones}

A lo largo de las páginas anteriores se ha tratado de exponer algunas de las limitaciones que presenta la hipótesis institucional, tal como ha sido argumentada por sus más calificados portavoces. La principal de las limitaciones alude al vano intento de encontrar una única y universal causa del subdesarrollo. Así como no existe una única estrategia de desarrollo, no existe tampoco un único diagnóstico de los factores que motivaron el atraso, ni siquiera cuando se refiere a una región definida.

Así, por ejemplo, si se considera a América Latina, es muy probable que en su rezago económico hayan influido factores muy diversos, entre los que se encuentran las condiciones geográficas (dificultades para el trasporte y la comunicación entre países y dentro de los países), el azar histórico (al postergar el proyecto industrializador en relación con el momento de la revolución de los transportes), las respuestas institucionales ofrecidas (especialmente por la dislocación entre instituciones formales e informales) y las opcio- nes de política económica adoptadas (Haber, 2000). A estos factores ha de sumarse el efecto que genera en el tiempo la dinámica acumulativa que aparece asociada a la existencia de rendimientos crecientes. Es difícil pensar que quepa reducir este conjunto de factores a una causa única.

Ahora bien, las insatisfacciones que provoca la lectura de los trabajos de AJR y ES no debiera llevar a desechar algunas de sus hipótesis, que son altamente sugerentes. Dicho de otro modo, es posible que haya que desprenderse del agua sucia de la bañera, pero sin arrojar al bebé con ella.

En concreto, parece plausible que la desigualdad (entendida en un sentido amplio, no solo referida a los ingresos) condicione la calidad de la acción colectiva $\mathrm{y}$, por tanto, influya sobre los niveles de eficiencia y credibilidad de las instituciones; y es razonable suponer también que estos dos aspectos -eficiencia y credibilidad del marco institucional - influyan sobre los resultados económicos y sobre la disposición al cambio social de los países implicados. No es necesario, por tanto, aceptar en su totalidad los planteamientos de Es para asumir que 
una mayor igualdad u homogeneidad en la población conduzca, con el tiempo, a una mayor inversión en bienes públicos e infraestructuras, y a instituciones que ofrezcan un acceso relativamente amplio a derechos de propiedad y a oportunidades económicas (Engerman y Sokoloff, 2006, p. 41). No obstante, convendría: i) estudiar más a fondo las vías a través de las que se canaliza la relación postulada entre desigualdad, instituciones y crecimiento, y ii) considerar el proceso de cambio institucional desde una perspectiva histórica más rica y compleja.

La segunda de estas cuestiones escapa a los propósitos del presente trabajo. No obstante, es necesario reconocer que se está muy lejos de disponer de una teoría amplia y convincente del cambio institucional (Lin y Nugent, 1995). La idea de que el proceso de cambio sigue una dinámica autoselectiva (como plantea la tradición evolucionista), que hace que de forma espontánea sobrevivan las instituciones más eficientes, no parece corresponderse con la realidad; como tampoco parece que lo haga el supuesto de que el cambio institucional responda exclusivamente a la lucha de intereses o a la búsqueda de ingresos de los agentes, individuales o colectivos, en el complejo mercado político (tal como sugiere la escuela de la elección pública). El proceso de cambio institucional parece notablemente más complejo, incorporando factores no solo materiales, sino también culturales (visiones del mundo, en suma) propios de la realidad social de cada caso (Chang y Evans, 2000). Esto es lo que hace difícil trasplantar modelos institucionales ya existentes o generar realidades institucionales ex novo en un determinado país. Por ello, el trabajo de los historiadores puede resultar básico para entender el cambio institucional.

Algo más se puede avanzar, sin embargo, en el análisis de la relación entre desigualdad y calidad institucional. En principio, cabe suponer que una institución constituye un contrato intertemporal, cuya eficacia aparece condicionada por dos factores: i) su eficiencia social, y ii) su credibilidad. Por eficiencia se entiende la capacidad que un marco institucional tiene para reducir costes de transacción y generar comportamientos compatibles con los incentivos de eficiencia: es decir, que dan lugar a un equilibrio en el juego institucional del que todos pueden salir beneficiados desde una perspectiva dinámica (o cuando menos, donde los ganadores puedan compensar a los perdedores). A su vez, por credibilidad se entiende la capacidad que el marco institucional tiene para modular la conducta de los agentes; es decir, para definir contratos intertemporales válidos. Ambos criterios son necesarios: no vale de nada disponer de una ins- titución supuestamente eficiente si no condiciona la conducta social, y a la vez nada garantiza que disponer de instituciones legitimadas dé lugar obligadamente a respuestas socialmente óptimas.

Pues bien, cabría contemplar la relación entre desigualdad y acción colectiva a través de tres argumentos no necesariamente incompatibles.

\section{a) Desigualdad y acción colectiva}

Una de las tareas básicas para las que se configuran las instituciones es para proveer de bienes públicos (de distinto tipo) a la sociedad. Buena parte de estos bienes públicos requieren una contribución cooperativa de los diversos agentes. La teoría de la acción colectiva apunta a dos hipótesis que relacionan, en un sentido negativo, los niveles de provisión del bien público con los niveles de igualdad del colectivo implicado. En primer lugar, en el caso de bienes públicos impuros, Olson (1965) adujo la "explotación" de los grandes contribuyentes por parte de los pequeños: los primeros tienden a asumir los costes de provisión, aun cuando no cooperen los pequeños contribuyentes, por ser mayores los beneficios netos que derivan del bien público. En segundo lugar, en el caso de los bienes públicos puros (en ausencia de soluciones de esquina), Cornes y Sandler (1996) demuestran la vigencia del principio de neutralidad: la provisión es independiente de la distribución del esfuerzo entre los diversos contribuyentes. En ambos casos la modelización se realiza bajo supuestos altamente restrictivos, considerando un modelo estático de dos jugadores.

Podría suponerse un planteamiento algo más complejo: Baland y Platteau (2007) y Bardhan (2005) exploran las consecuencias de la desigualdad, tomando en cuenta un juego extendido en el tiempo; y Bardhan y Singh (2004) analizan las posibilidades de un modelo con múltiples jugadores en el que es posible la formación de coaliciones. Los resultados de estos planteamientos son diferentes a los anteriormente señalados, apuntando a la existencia de una relación directa entre igualdad y eficiencia en la provisión de bienes públicos.

En concreto, Bardhan (2005) considera la existencia de desigualdad en un bien no transferible (capital privado, por ejemplo) y acepta incrementos de eficiencia que derivan del progreso tecnológico en la producción de insumos complementarios al capital. Aunque los incentivos para la cooperación son mayores en los miembros más ricos de la comunidad (con todo lo demás igual), el resultado puede cambiar de acuerdo a las estructuras de coalición que resultan de los niveles de desigualdad vigentes. Entre sus principales resultados Bardhan y Singh (2004) señalan que una reducción de la desigualdad puede incrementar 
la disposición a cooperar de quienes mejoran su posición relativa (recuadro 1). Es decir, bajo condiciones más cercanas a la dinámica social, la reducción de la desigualdad mejora la disposición de los agentes a cooperar. Esta posición ha sido objeto de estudios empíricos realizados por Bardhan y Dayton-Johnson (2007) en comunidades de gestión del agua en México y el sur de India, y por Cardenas (2007) en el caso de Colombia.

\section{Recuadro 1}

MODELO SIMPLE DE IMPACTO DEL INCREMENTO DE LA DESIGUALDAD SOBRE LA PROVISIÓN DE BIENES PÚBLICOS

Supongamos un modelo de asignación descentralizada en el que cada jugador juega independientemente. La producción total de un bien colectivo viene dada por $X=\sum x_{i}$. Y cada acción individual se agrega a través de la siguiente función lineal $z_{i}=b x_{i}+c X$. En caso de externalidades positivas y bien público puro, $c>0$ y $b=0 ; \mathrm{y}$ si el bien público es impuro, $c>0$ y $b>0$. En caso de externalidades negativas y un bien común, $c<0$ y $b>0$; y si es un bien privado, $c=0$ y $b>0$.

En un equilibrio Nash cada jugador elige una acción óptima dada la acción elegida por los demás. Es decir, cada jugador resuelve:

$\max \pi^{i}=f\left(w_{i}, z_{i}\right)-x_{i}$

Sea la función $g\left(w_{i}\right)>0$ el valor de $z_{i}$ que resuelve las condiciones de primer orden de la función anterior. Planteada como igualdad

$f_{2}\left(w_{i}, g\left(w_{i}\right)\right)(b+c)=1$

$g(w)$ representa el nivel del insumo colectivo $z$ que elegiría $i$ dada su riqueza $w$. Cada jugador puede afectar al bien colectivo solo a través de su contribución. Si denominamos $x$ la elección óptima de un jugador como

$\hat{x}_{i}=\frac{g\left(w_{i}\right)-c X}{b}$

Supongamos rendimientos decrecientes en el bien colectivo. De la ecuación anterior puede desprenderse $X=\frac{\sum g\left(w_{i}\right)}{b+m c}$ donde $m$ es el número de agentes en el equilibrio. Por lo tanto, $X$ es la suma de $m$ funciones cóncavas, de modo que ella será cóncava también. En este caso la contribución se maximiza cuando todos los agentes tienen igual cantidad del insumo privado.

Planteando esto en el caso de dos agentes, donde uno (1) tiene una riqueza $w+\varepsilon$ y otro (2) una riqueza $w-\varepsilon$, con $\varepsilon>0$. Consideremos las funciones de reacción de cada uno de los jugadores

$x_{1}=\frac{1}{b+c}\left[g(w+\varepsilon)-c x_{2}\right]$

$x_{2}=\frac{1}{b+c}\left[g(w-\varepsilon)-c x_{1}\right]$

Para apreciar un cambio distributivo, supóngase que se incrementa de $\varepsilon$ a $\varepsilon^{\prime}$, con lo que aumenta $x_{1}$ y se reduce $x_{2}$. En el caso de externalidades positivas, el gráfico da cuenta de los resultados. Es mayor el desplazamiento de $R_{2}$ que el de $R_{1}$.

Dado el supuesto de concavidad, la diferencia entre $g(w-\varepsilon)$ y $g\left(w-\varepsilon^{\prime}\right)$ es mayor que la que existe entre $g(w+\varepsilon)$ y $g\left(w+\varepsilon^{\prime}\right)$. El nuevo punto de equilibrio $(B)$ está abajo y a la izquierda de la recta de isocontribución. Es decir, al incrementarse la desigualdad se produce una pérdida agregada (la reducción de la contribución de 2 es superior al incremento de la contribución de 1). Este resultado es tributario de los supuestos aplicados más arriba.

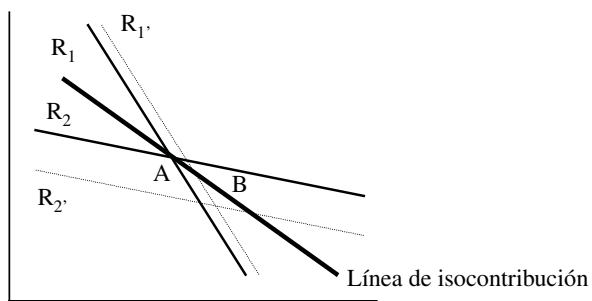

Fuente: basado en Bardhan, Ghatak y Karaivanov (2007). 


\section{b) Desigualdad e inestabilidad institucional}

En el apartado anterior se examina la relación entre desigualdad e incentivos para la acción cooperativa. Ese mismo problema podría contemplarse desde una perspectiva política. En principio, existen tres mecanismos básicos para hacer autorreplicable una institución: la tradición (se hace aquello que siempre se ha hecho); la coacción (se hace aquello obligado para evitar una sanción), y la disposición compartida (se hace aquello convenido porque se considera una opción razonable al problema de coordinación planteado). Aunque todas estas vías pueden ser eficaces, la última es la más resistente a la crítica y la que dota de mayor estabilidad al marco institucional.

No obstante, para que exista una disposición compartida, el equilibrio institucional debe satisfacer aceptablemente las expectativas de los agentes implicados. Es difícil que estos otorguen su respaldo a un marco institucional que, de forma sistemática, conduce a un muy desigual reparto de los beneficios derivados de la acción colectiva (Easterly, Ritzan y Woolcock, 2005). En esos casos lo que se producirá es un natural cuestionamiento del equilibrio institucional y un intento de alterar las reglas de juego previamente vigentes. Es esto lo que explica la estrecha asociación que existe entre la acusada desigualdad e inestabilidad institucional (Alesina y Perotti, 1996).

Es posible trasladar este planteamiento a una versión más formalizada si se considera que el mejor modo de representar una institución es a través de un juego extendido en el tiempo: es decir, un juego basado en la repetida interacción de los agentes. La distribución de los beneficios derivados de la acción colectiva es clave para que los jugadores se inclinen por la cooperación, incluso aunque la estructura estática del juego sea la propia del dilema del prisionero (recuadro 2 y

Recuadro 2

POSIBILIDADES COOPERATIVAS EN JUEGOS DINÁMICOS

Desde un punto de vista dinámico, las conclusiones que se derivan del dilema del prisionero pueden verse sustancialmente alterados con un incremento en las oportunidades de cooperación y de resultados eficientes. Para ilustrar este resultado se puede aplicar la estructura del dilema del prisionero al caso en que es posible hacer sucesivos movimientos. Cada agente tiene tres estrategias posibles: las dos ya conocidas — desertar y cooperar- y una tercera — reciprocidad - en la cual la respuesta de un jugador es respondida del mismo modo por el otro. Dado que las decisiones tienen consecuencias en el tiempo, debe considerarse la existencia de una tasa de descuento, de modo que el valor presente de un determinado beneficio neto $b$ sea para un número infinito de años: $b /(1-r)$. Supongamos que la oferta de bienes públicos cueste 10 y los beneficios obtenidos de esos bienes sea ocho para cada agente. Veamos los posibles escenarios.

Si los dos jugadores eligen la reciprocidad sobre las bases de la cooperación, en la primera ronda cada uno recibe 6/ (1-r) (casilla 1). El resultado es el mismo cuando uno decide cooperar y el otro actúa de modo recíproco o cuando ambos cooperan (casillas 2, 4 y 5). Por el contrario, cuando uno de los jugadores elige la reciprocidad y el otro la deserción, el primero obtiene un resultado de -2 en primera ronda y cero en el resto; y el otro 8 y 0 , respectivamente (casillas 3 y 7). Cuando de forma sistemática un jugador decide cooperar y el otro desertar, el primero obtiene -2/ (1-r) y el segundo 8/(1-r) (casillas 6 y 8). Y, finalmente, cuando ambos deciden no cooperar en todas las rondas ambos obtienen 0 (casilla 9).

Los dos jugadores no tienen una estrategia dominante, sino dos equilibrios de Nash. Uno es el habitual resultado del dilema del prisionero (la casilla 9), pero otro es una solución eficiente (casilla 1). En otras palabras, el mero hecho de introducir una perspectiva dinámica y permitir la existencia de una estrategia de reciprocidad basta para que se abra la posibilidad de una respuesta eficiente.

Dilema del prisionero con infinitos juegos

\begin{tabular}{|c|c|c|c|}
\hline & Reciprocidad & Cooperación & Deserción \\
\hline Reciprocidad & $6 /(1-r) ; 6 /(1-r)^{(1)}$ & $6 /(1-r) ; 6 /(1-r)^{(2)}$ & $-2,0 ; 8,0^{(3)}$ \\
\hline Cooperación & $6 /(1-r) ; 6 /(1-r))^{(4)}$ & $6 /(1-r) ; 6 /(1-r)^{(5)}$ & $-2 /(1-r) ; 8 /(1-r)^{(6)}$ \\
\hline Deserción & $-2,0 ; 8,0^{(7)}$ & $-2 /(1-r) ; 8 /(1-r)^{(8)}$ & $0 ; 0^{(9)}$ \\
\hline
\end{tabular}

Fuente: elaboración propia. 
Alonso, 2006). Lo que sugiere que la credibilidad de las instituciones depende altamente de la capacidad de estas para generar respuestas incluyentes.

\section{c) Desigualdad e instituciones informales}

Por último, la desigualdad social puede causar que segmentos de la sociedad traten de recluirse en instituciones informales como mecanismos de defensa y de protección colectiva. Estas instituciones no siempre resultan disfuncionales, pero en general muestran una menor adecuación al mercado y una mayor resistencia al cambio, como ya se ha señalado. Así pues, a través de este recurso se estaría dificultando tanto el desarrollo y eficacia de las instituciones formales como la flexibilidad y disposición al cambio del marco institucional disponible. En este caso la incidencia de la desigualdad opera a través de su impacto sobre el desarrollo de la informalidad. No se trata de un supuesto forzado, ya que los datos disponibles (todavía de baja calidad) revelan una relación directa entre los niveles de desigualdad de los países y el peso relativo de sus sectores informales (relación mostrada por Perry, Maloney y otros, 2007).

\section{Desigualdad y movilidad social}

Aun cuando se ha aludido a la desigualdad sin mayores precisiones, la pertinencia de los argumentos ofrecidos - especialmente, los dos últimos casos- se amplifica al referirse a la desigualdad horizontal —es decir, entre grupos humanos- en un entorno de limitada movilidad social. La disposición a la acción cooperativa se ve más seriamente dañada cuando la desigualdad genera mecanismos de solidaridad entre los grupos perjudicados: un hecho que sucede en caso de ser alta la desigualdad horizontal y de existir una baja movilidad social. Y, de igual modo, el recurso a las instituciones informales se acentúa en el caso de una elevada fragmentación social, lo que sucede cuando existe desigualdad horizontal y baja movilidad en la escala social.

El aspecto de la movilidad social resulta, a estos efectos, de notable relevancia. Argumentando en sentido contrario, la movilidad social, incluso en un contexto de desigualdad, atenúa el cuestionamiento del marco institucional existente: el éxito obtenido por alguno de los desfavorecidos hace alentar la esperanza del resto (es el "efecto túnel" que en su día sugirió Hirschman, 1981). En caso de que el éxito personal no llegue, se percibirá como consecuencia de la incapacidad propia (otros han podido), más que como una limitación del orden institucional vigente. Por ello, la ausencia de movilidad social, en un entorno de acusada desigualdad, alimenta el cuestionamiento del marco institucional existente, incrementando los niveles de inestabilidad y conflicto en el seno de las sociedades.

Las reflexiones anteriores son pertinentes para juzgar el caso de América Latina. Pues lo que caracteriza a la región no es solo un elevado nivel de desigualdad vertical, como revela el índice de desigualdad de Gini, sino también una notable desigualdad horizontal y una muy baja movilidad social (aunque este rasgo no es general y está peor estudiado). La desigualdad horizontal se revela en el análisis de los vectores de pobreza, que definen las probabilidades asimétricas de ser pobre en función de la condición rural o urbana de la población o de su origen étnico (indígenas, mestizos y blancos). Por su parte, la limitada movilidad social se traduce en que la pobreza de una generación (padres) es altamente predictiva de la pobreza de la generación siguiente (hijos). No es extraño entonces que en América Latina se padezca un problema significativo relacionado con la calidad de las instituciones. Superarlo no comporta solo mejorar las condiciones técnicas de la respuesta institucional, sino también actuar sobre la legitimidad social de las instituciones mismas, lo que tiene mucho que ver con los patrones distributivos a los que ellas aparecen asociadas.

\section{VII}

\section{Consideraciones finales}

La argumentación ofrecida conduce a algunas conclusiones que pueden ser de interés para pensar, una vez más, la agenda de desarrollo de América Latina. Planteadas de modo enunciativo:

1. Caracteriza a la región una muy acusada desigualdad social. Es discutible, sin embargo, que la explica- ción de ese rasgo pueda remitirse al momento de la colonización, cinco siglos atrás. Los estudios históricos parecen sugerir que la desigualdad (al igual que el atraso económico) es un fenómeno mucho más reciente, que debería situarse en el entorno de finales del siglo XIX. Factores como 
el modelo poscolonial de inserción internacional de América Latina (basado en la explotación de recursos naturales), el proceso de acogida de inmigración masiva en el entorno previo a la primera guerra mundial y la existencia de unas instituciones poco permeables al cambio social pueden haber contribuido a este resultado.

2. Señalar lo anterior no supone negar que el marco institucional tenga una función significativa en la determinación de la dinámica de crecimiento de largo plazo de los países. Es más, el análisis empírico parece respaldar la importancia que en el largo plazo tiene la calidad institucional. No obstante, este factor ha de combinarse con otros, entre los que se encuentra la accesibilidad a mercados del país en cuestión.

3. No se conoce, sin embargo, suficientemente cuáles son las claves del cambio institucional y existen dudas fundadas de que pueda definirse un marco institucional óptimo. Más bien, por el contrario, ha de suponerse que hay soluciones subóptimas que pueden ser funcionales a las condiciones específicas de una determinada economía, lo que obliga a considerar las condiciones locales para realizar un diagnóstico de la calidad institucional.

4 El marco institucional está compuesto de instituciones formales e informales. No obstante, por su mayor transparencia, las primeras tienen mayor capacidad de adaptación al cambio y permiten una mayor movilidad social. En las sociedades tradicionales o altamente fragmentadas, los sectores desfavorecidos suelen recurrir a instituciones informales. La presencia de esta informalidad puede ser una rémora para el cambio social.

5. La calidad de las instituciones depende de su eficiencia y de su credibilidad. Ambas dimensiones pueden ser afectadas por los niveles de desigualdad vigentes: la eficiencia, porque el juego estratégico conduzca a resultados que no sean compatibles con el marco de incentivos; la credibilidad, porque el desigual reparto de los frutos de la acción colectiva limite la disposición cooperativa de los agentes sociales perjudicados.

6. Al profundizar en las relaciones anteriores se adivinan cuando menos tres vías a través de las cuales la desigualdad influye en la calidad de las instituciones: i) puede limitar la provisión de bienes públicos; ii) altera la confianza en los contratos intertemporales que la institución propicia, y iii) alienta la búsqueda de respuestas institucionales informales. Todos estos factores pueden incidir sobre las posibilidades de crecimiento de una economía.

7. Por último, no sólo es relevante la desigualdad vertical, sino también - y muy especialmentela desigualdad horizontal y la falta de movilidad social. Estos dos últimos factores son centrales para entender la relación entre patrones distributivos y calidad institucional.
Acemoglu, D. y S. Johnson (2003): Unbundling Institutions, NBER Working Paper, No 9934, Cambridge, Massachusetts, National Bureau of Economic Research.

Acemoglu, D., S. Johnson y J.A. Robinson (2001): The colonial origins of comparative development: an empirical investigation, American Economic Review, vol. 91, № 5, Nashville, Tennessee, American Economic Association, diciembre.

(2002): Reversal of fortunes: geography and institutions in the making of the modern world income distribution, Quarterly Journal of Economics, vol. 117, No 4, Cambridge, Massachusetts, The MIT Press, noviembre.

(2006): Understanding prosperity and poverty: geography, institutions, and the reversal of the fortune, Understanding Poverty, A. Banerjee, R. Bénabou y D. Mookherjee (comps.), Nueva York, Oxford University Press.

Acemoglu, D. y J. Robinson (2000): Why did the West extend the franchise? Democracy, inequality, and growth in historical perspective, Quarterly Journal of Economics, Cambridge, Massachusetts, The MIT Press.

(2002): Economic Backwardness in Political Perspectives, NBER Working Paper, No 8831, Cambridge, Massachusetts, National Bureau of Economic Research, marzo.
Alesina, A., A. Devleeschauwer y otros (2003): Fractionalization, Journal of Economic Growth, vol. 8, № 2, Amsterdam, Springer Netherlands.

Alesina, A. y R. Perotti (1996): Income distribution, political instability and investment, European Economic Review, vol. 40, $\mathrm{N}^{\mathrm{o}}$ 6, Amsterdam, Elsevier.

Alonso, J.A. (2006): International Public Goods for Economic Development, inédito.

Baland, J.M. y J.PH. Platteau (2007): Collective action and the commons: the role of inequality, en J.M. Baland, P. Bardhan y S. Bowles (comps.), Inequality, Cooperation and Environmental Sustainability, Princeton, Princeton University Press.

Banco Mundial (2005): Informe sobre el desarrollo mundial 2006: equidad y desarrollo, Madrid, Mundi-Prensa Libros S.A.

(2006): World Development Indicators, Washington, D.C.

Banerjee, A. y L. Iyes (2005): History, institutions and economic performance: the legacy of colonial land tenure system in India, American Economic Review, vol. 95, № 4, Nashville, Tennessee, American Economic Association.

Bardhan, P. (2005): Scarcity, Conflict, and Cooperation: Essays in the Political and Institutional Economics of Development, Cambridge, Cambridge University Press. 
Bardhan, P. y J. Dayton-Johnson (2007): Inequality and the governance of water resources in Mexico and South India, en J.M. Baland, P. Bardhan y S. Bowles (comps.), Inequality, Cooperation and Environmental Sustainability, Princeton, Princeton University Press.

Bardhan, P. y N. Singh (2004): Inequality, coalitions, and collective action, inédito.

Bardhan, P., M. Ghatak y A. Karainov (2007): Inequality and collective action, en J.M. Baland, P. Bardhan y S. Bowles (comps.), Inequality, Cooperation and Environmental Sustainability, Princeton, Princeton University Press.

Bértola Flores, L. (2005): A 50 años de la curva de Kuznets: crecimiento económico y distribución del ingreso en Uruguay y otras economías de nuevo asentamiento desde 1870, Investigaciones de historia económica, $\mathrm{N}^{\circ} 3$, Madrid, Asociación Española de Historia Económica.

Bourguignon, F. y Ch. Morrison (2002): The size distribution of income among world citizens, 1820-1990, American Economic Review, vol. 92, № 4, Nashville, Tennessee, American Economic Association, septiembre.

Bulmer-Thomas, V. (1994): The Economic History of Latin America since Independence, Cambridge, Cambridge University Press.

Cardenas, J.C. (2007): Wealth inequality and overexploitation of the commons: field experiments in Colombia, en J.M. Baland, P. Bardhan y S. Bowles, Inequality, Cooperation and Environmental Sustainability, Princeton, Princeton University Press.

Carmagnani, M. (2004): El otro Occidente. América Latina desde la invasión europea hasta la globalización, México, D.F., Fondo de Cultura Económica/Colegio de México.

Chang, H-J. y P. Evans (2000): The role of institutions in economic change, documento preparado para la Conferencia "The Other Canon".

Coatsworth, J.H. (2005): Structures, endowments, and institutions in the economic history of Latin America, Latin American Research Review, vol. 40, No 3, Austin, Texas, University of Texas Press.

(2007): Inequality, Institutions, and Economic Growth in Latin America, inédito.

Coatsworth, J.H. y G. Tortella (2002): Institutions and Long-Run Economic Performance in Mexico and Spain, 1800-2000, documento preparado para el XIII Congreso de la Asociación Internacional de Historia Económica.

Cornes, R. y T. Sandler (1996): The Theory of Externalities, Public Goods, and Club Goods, Cambridge, Cambridge University Press.

De Ferranti, D., G. Perry y otros (2004): Inequality in Latin America: Breaking with History?, Washington, D.C., Banco Mundial.

Diamond, J. (1998): Guns, Germs and Steel: the Fates of Human Societies, Nueva York, W.W. Norton. (2005): Collapse, Nueva York, Penguin Group.

Dobado, R. (2007): Herencia colonial y desarrollo económico en Iberoamérica, inédito.

Easterly, W., J. Ritzan y M. Woolcock (2005), Social cohesion, institutions, and growth, Washington, D.C., Banco Mundial, inédito.

Elliott, J.H. (2006): Imperios del mundo atlántico. España y Gran Bretaña en América (1492-1830), Madrid, Santillana Ediciones Generales.

Engerman, S.L. y K.L. Sokoloff (1997): Factor endowments: institutions and differential paths of growth among new world economies. A view from economic historians of the United States, en S. Haber, How Latin America Fell Behind: Essays on the Economic Histories of Brazil and Mexico, 1800-1914, Stanford, Stanford University Press.

(2002): Factor Endowments, Inequality, and Paths of Development Among the New World Economies, NBER Working Paper, $N^{\circ}$ 9259, Cambridge, Massachusetts, National Bureau of Economic Research.
(2005): Colonialism, Inequality, and Long-run Paths of Development, NBER Working Paper, № 11057, Cambridge, Massachusetts, National Bureau of Economic Research,

(2006): Colonialism, inequality, and long-run paths of development, en A.V. Banerjee, R. Bénabou y D. Mookherjee (comps.), Understanding Poverty, Oxford, Oxford University Press.

Engerman, S.L., S.H. Haber y K.L. Sokoloff (2000): Inequality, institutions, and differential paths of growth among new world economies, en C. Menard (comp.), Institutions, Contracts, and Organization, Cheltenham, Edward Elgar.

Frankel, J.A. y D. Romer (1999): Does trade cause growth?, American Economic Review, vol. 89, No 3, Nashville, Tennessee, American Economic Association, junio.

Gallup, J.L., A. Gaviria y E. Lora (2003): América Latina: ¿condenada por su geografía?, Bogotá, D.C., Banco Interamericano de Desarrollo/Alfaomega Colombiana.

Gallup, J.L., J. Sachs y A. Mellinger (1998): Geography and Economic Development, NBER Working Paper, $\mathrm{N}^{\circ}$ 6849, Cambridge, Massachusetts, National Bureau of Economic Research.

Gelman, J. (2007): ¿Crisis postcolonial en las economías sudamericanas? Los casos del Río de la Plata y Perú, inédito.

Greif, A. (1994): Cultural beliefs and the organization of society: a historical and theoretical reflection on collectivist and individualist societies, Journal of Political Economy, vol. 102, Chicago, The University of Chicago Press.

(2004): Institutions: Theory and History, inédito.

Greif, A., P. Milgrom y B. Weingast (1994): Coordination, commitment and enforcement: the case of the merchant guild, Journal of Political Economy, vol. 102, Chicago, The University of Chicago Press.

Haber, S. (1997): How Latin America Fell Behind: Essays on the Economic Histories of Brazil and Mexico, 1800-1914, Stanford, Stanford University Press.

(comp.) (2000): Political Institutions and Economic Growth in Latin America, Stanford, Hoover Institutions Press.

Hirschman, A.O. (1981): Essays in Trespassing, Cambridge, Cambridge University Press.

Islam, R. y C. Montenegro (2002): What Determines the Quality of Institutions?, Policy Research Working Paper Series, № 2764, Washington, D.C., Banco Mundial.

Kaufmann, D., A. Kraay y M. Mastruzzi (2005): Governance Matters IV: Governance Indicators for 1996-2004, Washington, D.C., Banco Mundial.

Landes, D.S. (1998): The Wealth and Poverty of Nations: Why Some Are So Rich and Some So Poor, Nueva York, W.W. Norton.

Lin, J.Y. y J.B. Nugent (1995): Institutions and economic development, en J. Behrman y T.N. Srinivasan (comps.), Handbook of Economic Development, vol 3, Amsterdam, North-Holland.

Mann, Ch.C. (2006): 1491. Una nueva historia de las Américas antes de Colón, Bogotá, D.C., Taurus.

Miño, M. (1991): Obrajes y tejedores de Nueva España 1700-1810, Madrid, Instituto de Estudios Fiscales.

North, D.C. (1990): Institutions, Institutional Change and Economic Performance, Nueva York, Cambridge University Press.

(1993): The New Institutional Economics and Development, Saint Louis, Washington University.

(2005): Understanding the Process of Economic Change, Princeton, Princeton University Press.

Olson, M. (1965): The Logic of Collective Action. Public Goods and Theory of Groups, Cambridge, Cambridge University Press.

Perry, G., O. Arias y otros (2006): Poverty Reduction and Growth: Virtuous and Vicious Circles, Washington, D.C., Banco Mundial.

Perry, G., W. Maloney y otros (2007): Informalidad: escape y exclusión, Washington, D.C., Banco Mundial.

Prados de la Escosura, L. (2005): Growth Inequality and Poverty in Latin America: Historical Evidence, Controlled Conjectures, 
Working Papers in Economic History, No 54104, Madrid, Universidad Carlos III.

Pritchett, L. (1997): Divergence, big time, Journal of Economic Perspectives, vol. $11 \mathrm{~N}^{\mathrm{o}} 3$, Nashville, Tennessee, American Economic Association.

Przeworski, A. y C. Curvale (2005): Does politics explain the economic gap between the United States and Latin America?, Nueva York, New York University, inédito.

Quian, Y. (2003): How reform worked in China, en D. Rodrik (comp.), In Search of Prosperity. Analytic Narratives on Economic Growth, Princeton, Princeton University Press.

Rodrik, D., A. Subramanian y F. Trebbi (2002): Institutions Rule: The Primacy of Institutions over Geography and Integration in Economic Development, IMF Working Paper, No 02/189, Washington, D.C., Fondo Monetario Internacional.
Sachs, J. (2001): Tropical Underdevelopment, NBER Working Paper Series, $N^{\circ} 8119$, Cambridge, Massachusetts, National Bureau of Economic Research.

Sokoloff, K. y S.L. Engerman (2000): Institutions, factor endowments, and paths of development in the new world, Journal of Economic Perspectives, vol. 14, $\mathrm{N}^{\circ} 3$, Nashville, Tennessee, American Economic Association.

Velasco, C., E. Flores y otros (1988): Estado y minería en México, 1767-1910, México, D.F., Fondo de Cultura Económica.

Williamson, J. (1999): Real wages, inequality and globalization in Latin America before 1940, Revista de historia económica, vol. 17, Madrid, Fundación SEPI.

Williamson, O.E. (1985): Economic Institutions of Capitalism, Nueva York, The Free Press. 